\title{
Exceptional Single-Molecule Transport Properties of Ladder-Type Heteroacene Molecular Wires
}

Zhengxu Cai, Wai-Yip Lo, Tianyue Zheng, Lianwei Li, Na Zhang, Yubing Hu, and Luping $\mathrm{Yu}^{*}$

Department of Chemistry and the James Franck Institute, The University of Chicago, Chicago, IL 60637, USA.

Contents:

Page

1. Synthesis of the molecular wires

S2

2. Surface characterizations: XPS and CV

S6

3. Average $I-V$ curves and $d I / d V$ spectra

S8

4. DFT calculations

S9 


\section{Synthesis of the molecular wires}
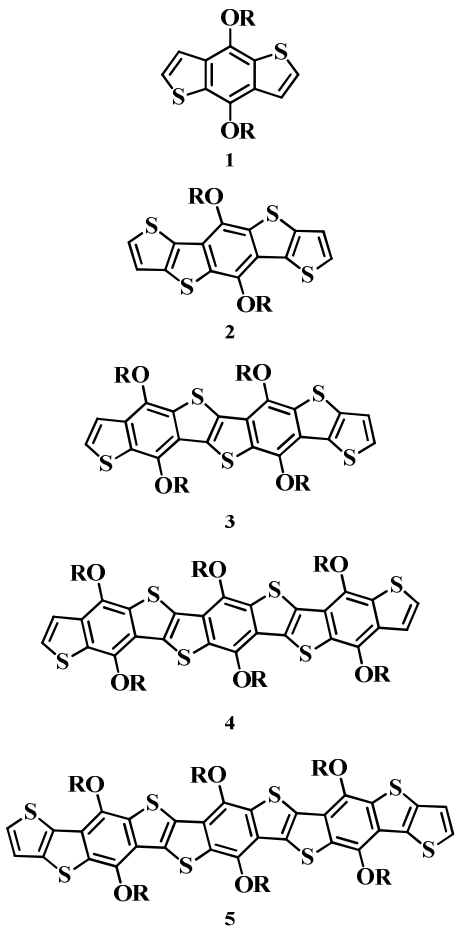

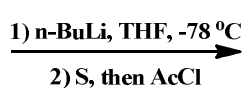

2) $\mathrm{S}$, then $\mathrm{AcCl}$

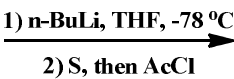

2) S, then AcCl

$\underset{\text { 1) } \mathrm{n}-\mathrm{BuLi}, \mathrm{THF},-78^{\circ} \mathrm{C}}{\underset{\text { 2) } \mathrm{S} \text {, then AcCl }}{\longrightarrow}}$

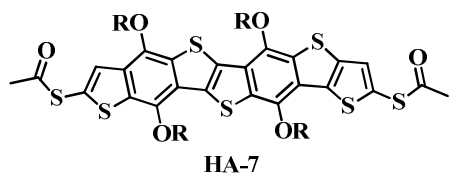

$\underset{\text { 1) n-BuLi, THF, }-78^{\circ} \mathrm{C}}{\stackrel{\longrightarrow}{\longrightarrow} \text {, then } \mathrm{AcCl}}$
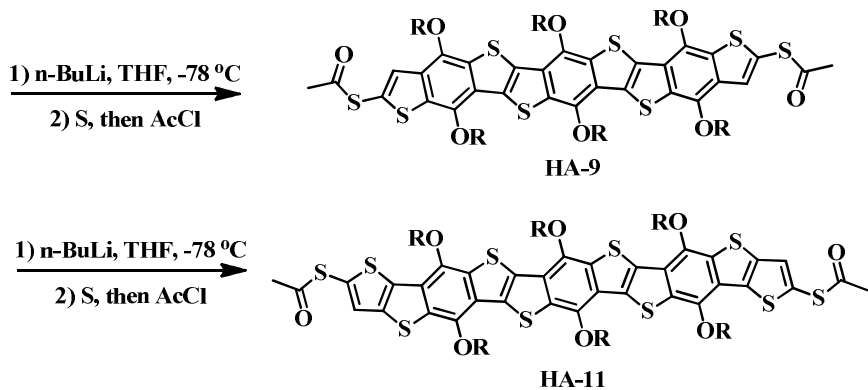

R = 2-Ethylhexyl(EH)
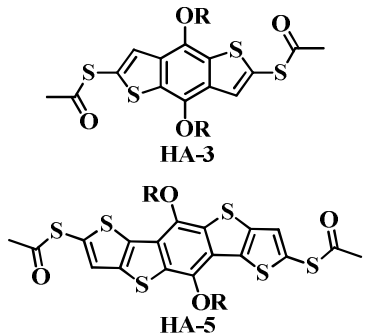

Scheme S1. Synthetic route of the molecular wires

All of the chemicals were purchased from Aldrich except for tetrakis(triphenylphosphine)palladium from Strem Chemicals. All reagents purchased commercially were used without further purification except for toluene and tetrahydrofuran (THF), which were dried over sodium/benzophenone. ${ }^{1} \mathrm{H}$ NMR and ${ }^{13} \mathrm{C}$ NMR spectra were recorded on a Bruker DRX-400 spectrometer or Bruker DRX-500, with tetramethylsilane as an internal reference. Matrix-assisted laser desorption ionization time-of-flight (MALDI-TOF) mass spectra were recorded using a Bruker Ultraflextreme MALDI-TOF/TOF mass spectrometer with dithranol as the matrix. Compounds $\mathbf{1 - 4}{ }^{1}, \mathbf{5}^{2}$ were prepared by our previous work. 
Heteroacene(HA)-3: Benzodithiophene (1) (400 mg, $0.90 \mathrm{mmol}, 1.0$ equiv) was dissolved in dry THF $(25 \mathrm{~mL})$, and the solution was cooled to $-78{ }^{\circ} \mathrm{C} . \mathrm{n}-\mathrm{BuLi}(2.5 \mathrm{M}$ in hexanes, 0.79 $\mathrm{mL}, 1.97 \mathrm{mmol}, 2.2$ equiv) was added dropwise via a syringe, and the reaction was allowed to stir at $-78{ }^{\circ} \mathrm{C}$ for $30 \mathrm{~min}$, and $0{ }^{\circ} \mathrm{C}$ for $1 \mathrm{~h}$. Dry sulfur $(86 \mathrm{mg}, 2.68 \mathrm{mmol}, 3.0$ equiv) powder was added in one portion, and the reaction was stirred at $0{ }^{\circ} \mathrm{C}$ for another hour, before $\mathrm{AcCl}(200 \mu \mathrm{L}, 2.68 \mathrm{mmol}, 3.0$ equiv) was added via a syringe. The reaction was allowed to warm to RT and stirred overnight $(15 \mathrm{~h})$, before pouring into water $(50 \mathrm{~mL})$. The aqueous layer was extracted with $\mathrm{Et}_{2} \mathrm{O}(30 \mathrm{~mL} \times 2)$, and the combined organic layers were washed with brine $(10 \mathrm{~mL})$, dried over $\mathrm{MgSO}_{4}$, filtered, and concentrated to provide yellow solid. Purification by flash chromatography with a gradient of $1: 1$ hexane: $\mathrm{CH}_{2} \mathrm{Cl}_{2}$ provided HA-3 as a pale yellow solid (282 mg, $52.9 \%$ yield). ${ }^{1} \mathrm{H}$ NMR $\left(\mathrm{CDCl}_{3}, \mathrm{ppm}\right): \delta 7.54(\mathrm{~s}, 2 \mathrm{H})$, $4.16(\mathrm{q}, 4 \mathrm{H}), 2.47(\mathrm{~s}, 6 \mathrm{H}), 1.76(\mathrm{~m}, 2 \mathrm{H}), 1.63(\mathrm{~m}, 2 \mathrm{H}), 1.52-1.36(\mathrm{~m}, 14 \mathrm{H}), 0.99(\mathrm{t}, 6 \mathrm{H}), 0.92$ (t, 6H). ${ }^{13} \mathrm{C} \mathrm{NMR}\left(\mathrm{CDCl}_{3}, \mathrm{ppm}\right): \delta 192.9,144.2,132.3,131.6,128.8,127.4,40.6,30.4,29.9$, 29.1, 23.8, 23.1, 14.1, 11.3. MS (MALDI-TOF/) m/z: $\mathrm{C}_{30} \mathrm{H}_{42} \mathrm{O}_{4} \mathrm{~S}_{4}$, Calcd, 594.2. Found, $\left(\mathrm{M}^{+}\right), 594.1$.

Heteroacene(HA)-5. This was prepared following the general procedure given for the preparation of HA-3. From 2 (80 $\mathrm{mg}, 0.14 \mathrm{mmol})$ there was obtained HA-5 as yellow solid (52 mg, $51.4 \%$ yield). ${ }^{1} \mathrm{H}$ NMR $\left(\mathrm{CDCl}_{3}, \mathrm{ppm}\right): \delta 7.37(\mathrm{~s}, 2 \mathrm{H}), 4.20(\mathrm{~d}, 4 \mathrm{H}), 2.44(\mathrm{~s}, 6 \mathrm{H})$, $1.99(\mathrm{~m}, 2 \mathrm{H}), 1.69(\mathrm{~m}, 2 \mathrm{H}), 1.61-1.59(\mathrm{~m}, 6 \mathrm{H}), 1.40(\mathrm{~m}, 8 \mathrm{H}), 1.02(\mathrm{t}, 6 \mathrm{H}), 0.91(\mathrm{t}, 6 \mathrm{H}) .{ }^{13} \mathrm{C}$ NMR $\left(\mathrm{CDCl}_{3}, \mathrm{ppm}\right): \delta 193.9,144.1,136.9,136.8,131.0,128.9,128.6,125.7,40.7,30.2$, 29.7, 29.1, 23.7, 23.1, 14.1, 11.2. MS (MALDI-TOF/) m/z: $\mathrm{C}_{34} \mathrm{H}_{42} \mathrm{O}_{4} \mathrm{~S}_{6}$, Calcd, 706.1. Found, $\left(\mathrm{M}^{+}\right), 706.0$. 
Heteroacene(HA)-7. This was prepared following the general procedure given for the preparation of HA-3. From 3 (126 mg, $0.14 \mathrm{mmol}$ ) there was obtained HA-7 as yellow solid (42 mg, $28.7 \%$ yield). ${ }^{1} \mathrm{H}$ NMR $\left(\mathrm{CDCl}_{3}, \mathrm{ppm}\right): \delta 7.59$ (s, 1H), 7.41, (s, 1H), 4.27 (m, 8H), $2.49(\mathrm{~s}, 3 \mathrm{H}), 2.47(\mathrm{~s}, 3 \mathrm{H}), 2.08(\mathrm{~m}, 2 \mathrm{H}), 1.77(\mathrm{~m}, 4 \mathrm{H}), 1.64(\mathrm{~m}, 8 \mathrm{H}), 1.40(\mathrm{~m}, 18 \mathrm{H}), 1.24(\mathrm{~m}$, 4H), $1.05(\mathrm{~m}, 12 \mathrm{H}), 0.93(\mathrm{~m}, 12 \mathrm{H}) .{ }^{13} \mathrm{C} \mathrm{NMR}\left(\mathrm{CDCl}_{3}, \mathrm{ppm}\right): \delta 194.0,193.1,145.2,144.3$, $144.3,143.4,137.0,136.8,132.7,132.0,131.7,131.3,130.7,130.2,129.1,128.7,128.7$, $126.7,126.2,125.6,125.4,40.8,40.7,30.4,30.3,30.0,29.7,29.2,23.8,23.7,23.1,14.1,11.3$, 11.2. MS (MALDI-TOF/) m/z: $\mathrm{C}_{56} \mathrm{H}_{76} \mathrm{O}_{6} \mathrm{~S}_{7}$, Calcd, 1068.4. Found, $\left(\mathrm{M}^{+}\right)$, 1068.4.

Heteroacene(HA)-9. This was prepared following the general procedure given for the preparation of HA-3. From 4 (190 mg, $0.15 \mathrm{mmol})$ there was obtained HA-9 as light orange solid (145 mg, $68.4 \%$ yield). ${ }^{1} \mathrm{H}$ NMR $\left(\mathrm{CD}_{2} \mathrm{Cl}_{2}, \mathrm{ppm}\right): \delta 7.53(\mathrm{~s}, 2 \mathrm{H}), 4.32(\mathrm{~d}, 4 \mathrm{H}), 4.26(\mathrm{~d}$, 4H), $4.20(\mathrm{~d}, 4 \mathrm{H}), 2.42(\mathrm{~s}, 6 \mathrm{H}), 2.12(\mathrm{~m}, 2 \mathrm{H}), 2.08(\mathrm{~m}, 2 \mathrm{H}), 1.70-1.35(\mathrm{~m}, 50 \mathrm{H}), 1.05(\mathrm{~m}$, 18H), 0.92 (m, 18H). ${ }^{13} \mathrm{C}$ NMR $\left(\mathrm{CD}_{2} \mathrm{Cl}_{2}, \mathrm{ppm}\right): \delta 192.9,145.2,144.4,143.3,132.7,131.8$, $131.6,130.8,130.0,129.0,127.0,125.8,125.2,40.8,40.8,30.4,30.4,30.3,30.0,29.8,29.3$, $29.3,23.8,23.8,23.7,23.2,23.2,23.2,14.0,14.0,11.2,11.2,11.1,11.1,11.0,11.0 . \mathrm{MS}$ (MALDI-TOF/) m/z: $\mathrm{C}_{78} \mathrm{H}_{110} \mathrm{O}_{8} \mathrm{~S}_{8}$, Calcd, 1430.6. Found, $\left(\mathrm{M}^{+}\right), 1430.5$.

Heteroacene(HA)-11. This was prepared following the general procedure given for the preparation of HA-3. From 5 (30 $\mathrm{mg}, 0.02 \mathrm{mmol})$ there was obtained HA-11 as orange solid (13.2 mg, $39.8 \%$ yield). ${ }^{1} \mathrm{H}$ NMR $\left(\mathrm{CDCl}_{3}, \mathrm{ppm}\right): \delta 7.39(\mathrm{~s}, 2 \mathrm{H}), 4.35(\mathrm{~d}, 4 \mathrm{H}), 4.32(\mathrm{~d}, 4 \mathrm{H})$, $4.27(\mathrm{~d}, 4 \mathrm{H}), 2.46(\mathrm{~s}, 6 \mathrm{H}), 2.07(\mathrm{~m}, 6 \mathrm{H}), 1.80(\mathrm{~m}, 6 \mathrm{H}), 1.70-1.58(\mathrm{~m}, 38 \mathrm{H}), 1.23(\mathrm{~m}, 4 \mathrm{H})$, $1.06(\mathrm{~m}, 18 \mathrm{H}), 0.93(\mathrm{~m}, 18 \mathrm{H}) .{ }^{13} \mathrm{C} \mathrm{NMR}\left(\mathrm{CDCl}_{3}, \mathrm{ppm}\right): \delta 194.0,144.4,143.3,137.0,138.8$, $132.1,132.0,131.2,130.9,130.5,130.2,128.8,128.7,126.2,125.9,125.4,40.8,40.8,30.4$, 
(MALDI-TOF/) m/z: $\mathrm{C}_{142} \mathrm{H}_{110} \mathrm{O}_{8} \mathrm{~S}_{10}$, Calcd, 1542.5. Found, (M+H), 1543.8.

Synthesis and Characterization: The synthesis of all the heteroacene compounds were shown in Scheme S1. The synthesis started from compounds $\mathbf{1 - 5}$, which was prepared according to our reported procedures. Thiol group was introduced into the heteroacenes, respectively, by a general method. Treatment of 1-5 with n-butyl lithium at $-78{ }^{\circ} \mathrm{C}$, followed by the addition of dry sulfur powder led to thiol groups. Finally, $\mathrm{AcCl}$ was added to protect thiol groups afforded yellow or orange solids heteroacenes (HA-3, 5, 7, 9 and 11), respectively, after purification. The chemical structures of $\mathbf{H A - 3}, \mathbf{5}, \mathbf{7 , 9}$ and 11 were characterized with NMR and MS data. 


\section{Surface characterizations: XPS and CV}

X-ray photoelectron spectroscopy (XPS) was performed on the Thermo Scientific ESCALab 250Xi using $200 \mathrm{~W}$ monochromated $\mathrm{Al} \mathrm{K \alpha}$ radiation. The $500 \mu \mathrm{m}$ X-ray spot was used for XPS analysis. The base pressure in the analysis chamber was about $3 \times 10^{-10}$ mbar. Typically, the hydrocarbon $\mathrm{C} 1 \mathrm{~s}$ line at $284.8 \mathrm{eV}$ from adventitious carbon is used for energy referencing.
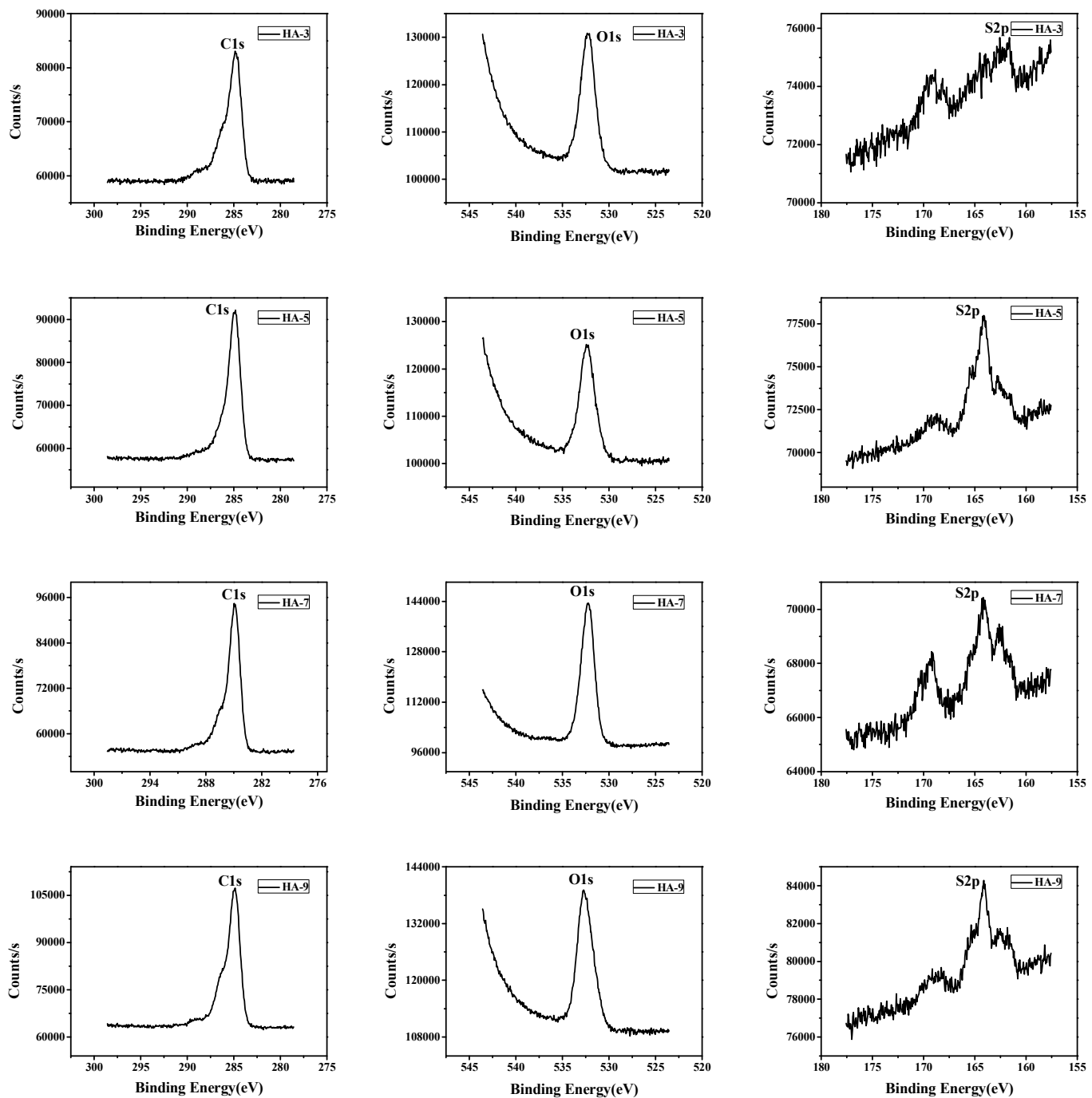

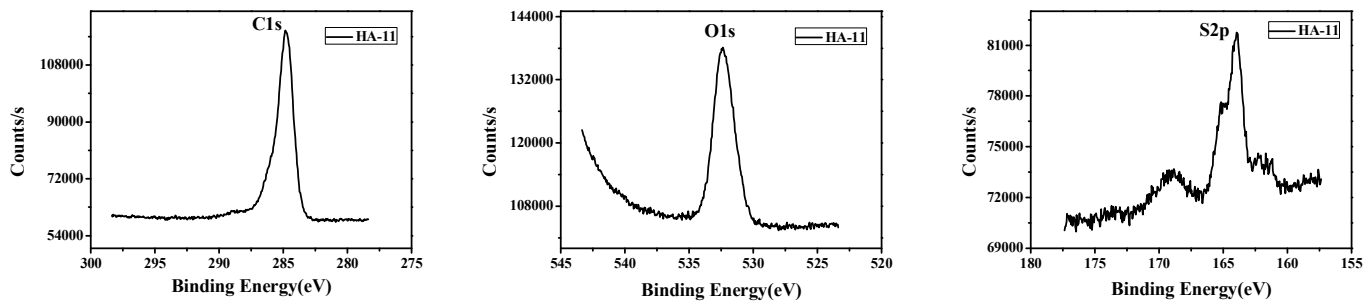

Figure S2| XPS carbon 1s, oxygen 1s, sulfur 2p spectra of HA3, HA5, HA7, HA9, and HA11. The extra higher energy peaks on the sulfur spectra $(\sim 169 \mathrm{eV})$ correspond to oxidized sulfur (e.g. sulfoxide).

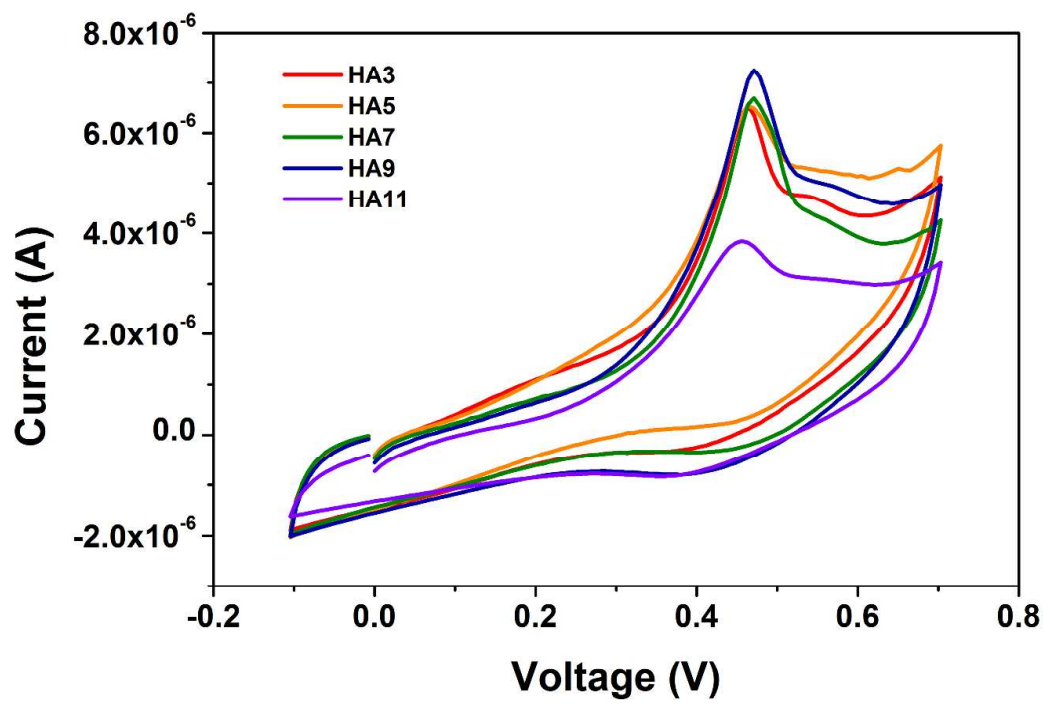

Figure S3| Cyclic voltammograms of ferrocene functionalized heteroacene molecular wire monolayer on gold.

Surface coverage of the molecule on the gold substrate were determined from the voltammograms recorded according to the equation:

$$
\Gamma=\frac{Q_{F e}}{n F A r}
$$

where $Q_{F e}$ is the charge consumed for the oxidation-reduction process of the ferrocene groups, $n$ is the number of electrons involved in the electron transfer process ( $n=1$ for ferrocene), $A$ is the geometric surface area of the electrode $\left(0.6362 \mathrm{~cm}^{2}\right), r$ is the scan rate, and $F$ is the 
faraday constant. Values of $Q_{F e}$ were obtained by the integration of the faradaic current peaks from the voltammograms.

\section{Average I-V curves and dI/dV spectra}
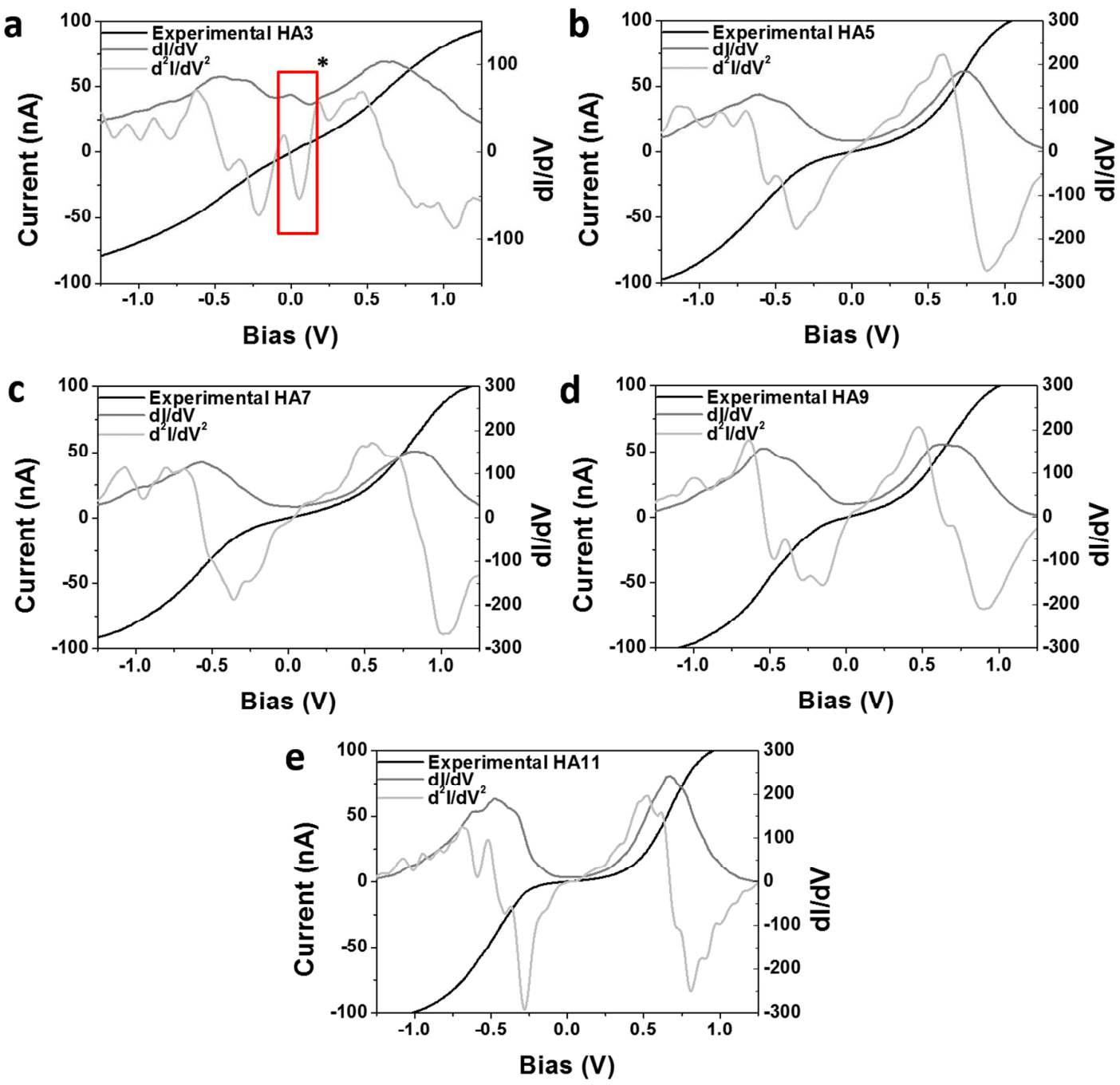

Figure S4| Average I-V curves, dI/dV and $\mathrm{d}^{2} \mathrm{I} / \mathrm{dV}^{2}$ spectra of HA3 to HA11 (a to e). Average I-V curves are constructed from ca. 500 individual curves. *The peaks observed in the red box are artifacts originated from the disconnected data in the I-V curves and should not be interpreted as part of the junction transport property. 


\section{DFT Calculations}

The molecular geometries of the molecules were optimized, and their orbital energies and charge distributions calculated using the B3LYP DFT function with basis set $6-31 \mathrm{G}^{* *}$ as implemented in Gaussian 09.

HA3 HOMO

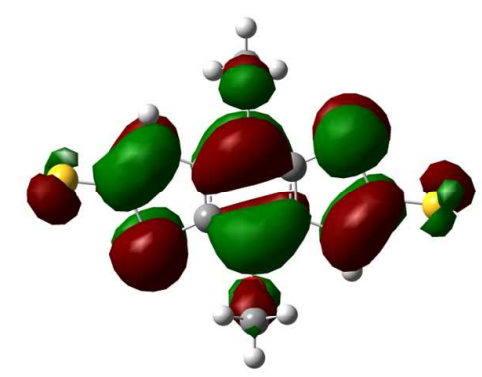

HA5 HOMO

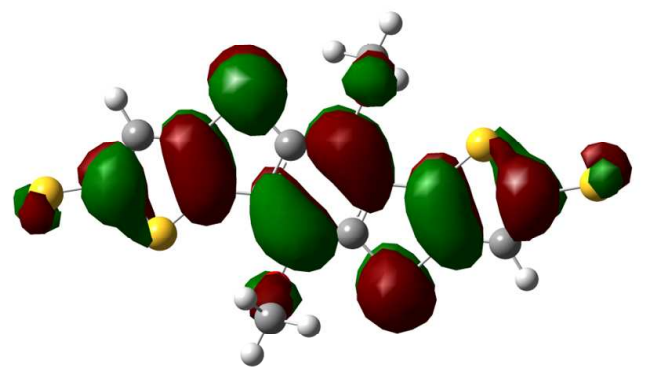

HA7 HOMO
HA3 LUMO

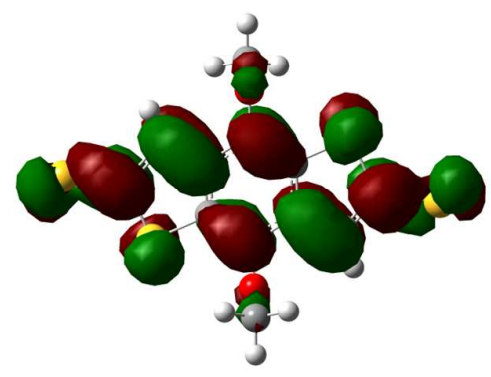

HA5 LUMO

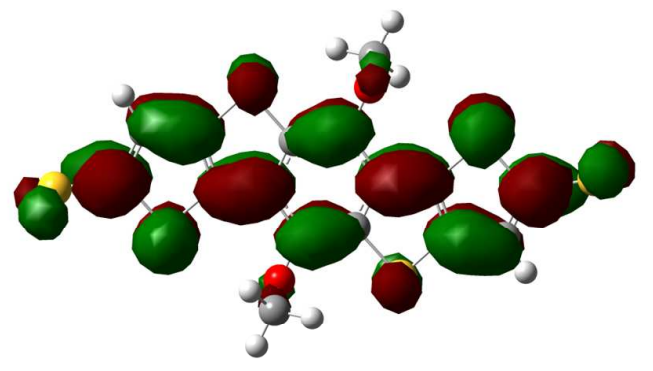

HA7 LUMO 


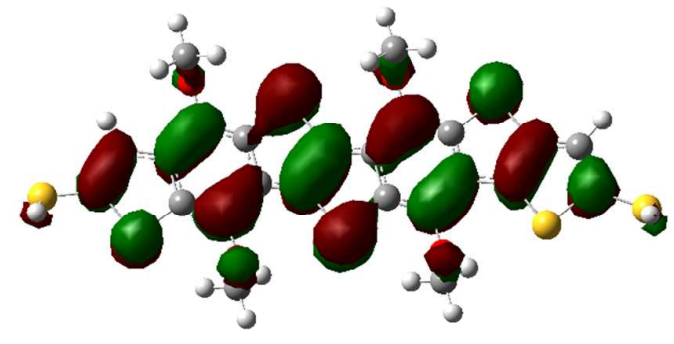

HА9 HOMO

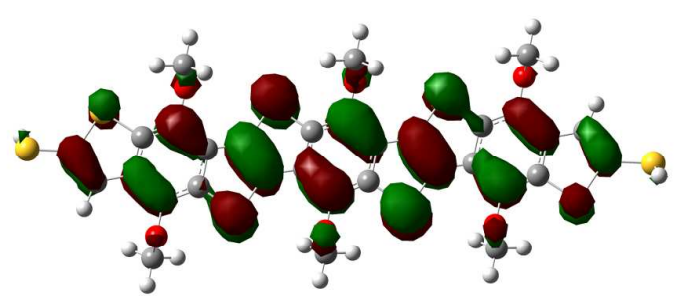

HA11 HOMO

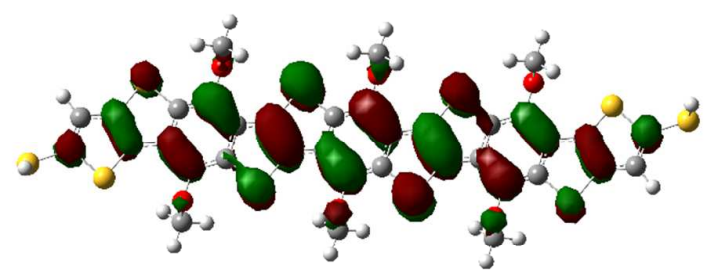

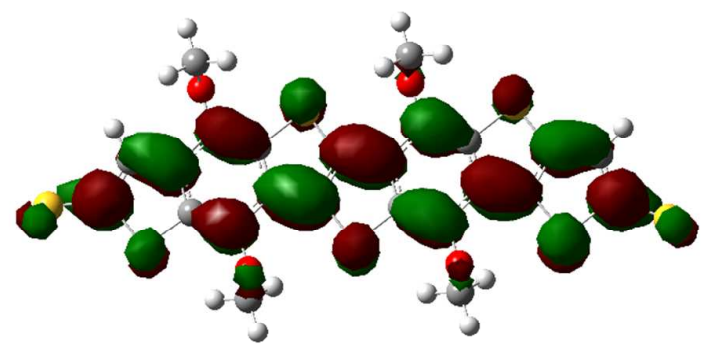

HA9 LUMO

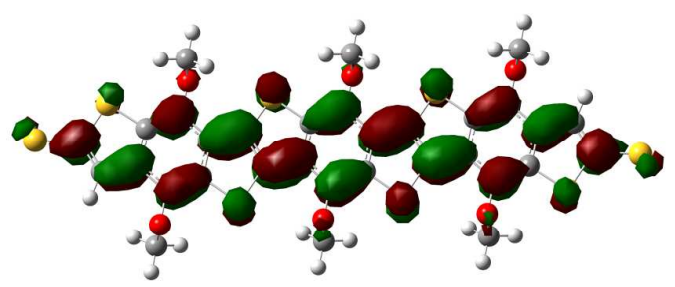

HA11 LUMO

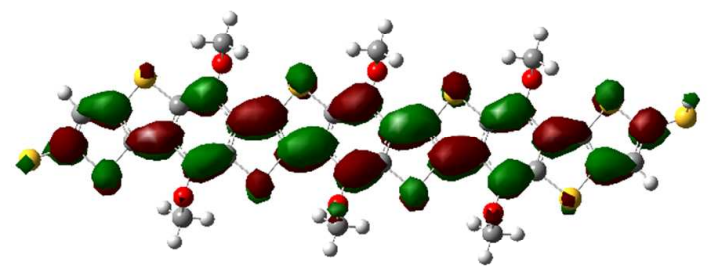

References:

1. Zheng, T., Lu, L., Jackson, N. E., Lou, S. J., Chen, L. X.\& Yu, L. 2014, 47, 6252-6259.

2. Zheng, T., Cai, Z., R., H.-W., Yau, S. H., Shaparov, V., GoodsonIII, T.\& Yu, L. J. Am.

Chem. Soc. 2016, 138, 868-875. 